\title{
Functional Capacity and Psychosocial Correlates of Exercise in Nigerian Patients with Hypertension
}

\author{
Taofeek 0. Awotidebe1, Victor O. Adeyeye ${ }^{2}$, Rita N. Ativie ${ }^{3}$, Rufus A. Adedoyin ${ }^{1 *}$, \\ Adebusola 0. Borode1, Michael 0. Balogun ${ }^{2,4}$, Mukadas A. Akindele ${ }^{5}$ \\ ${ }^{1}$ Department of Medical Rehabilitation, College of Health Sciences, Obafemi Awolowo University, Ile-Ife, Nigeria \\ ${ }^{2}$ Cardiac Care Unit, Obafemi Awolowo University Teaching Hospitals Complex, Ile-Ife, Nigeria \\ ${ }^{3}$ Department of Medical Rehabilitation, Faculty of Health Sciences and Technology, University of Nigeria, Enugu, \\ Nigeria \\ ${ }^{4}$ Department of Medicine, College Health Sciences, Obafemi Awolowo University, Ile-Ife, Nigeria \\ ${ }^{5}$ Department of Physiotherapy, College of Medical Sciences, Bayero University Kano, Kano, Nigeria \\ Email: *radedoyi@yahoo.com
}

Received 8 January 2016; accepted 9 July 2016; published 12 July 2016

Copyright (C) 2016 by authors and Scientific Research Publishing Inc.

This work is licensed under the Creative Commons Attribution International License (CC BY).

http://creativecommons.org/licenses/by/4.0/

(c) (i) Open Access

\section{Abstract}

Objectives: Psychosocial factors are important determinants of cardiovascular health outcomes in rehabilitation. However, the relationship between exercise performance and individual factors remained poorly understood. This study investigated the relationship between functional capacity and psychosocial correlates of exercise in Nigerian patients with hypertension. Study Design and Setting: This quasi-experimental study recruited 120 patients with hypertension $(\geq 140 / 90 \leq$ $179 / 109 \mathrm{mmHg}$ ) from the Cardiac Care Unit of a Nigerian university teaching using purposive sampling technique. Functional capacity was assessed using the 6-minute walk test and maximum oxygen consumption ( $\mathrm{VO}_{2}$ max) was estimated. Participants also underwent a 30-minute selfpaced walking exercise. Thereafter, psychosocial correlates of exercise including exercise self-efficacy (ESE), social support (SoS), perceived exercise barrier (PEB) and socio-economic status (SES) were assessed using validated questionnaires. Descriptive and inferential statistics were used to analyze data. Alpha level was set at $p<0.05$ of significance. Results: A majority of the participants demonstrated high ESE (75.0\%), moderate SoS (60.9\%) and low PEB (71.7\%). More than half (58.4\%) of the participants were in the middle SES. Male and female participants were comparable in ESE scores $(p=0.554)$, SoS $(p=0.362)$ and six-minute walk distance (6-MWD) $(p=0.194)$ except in body mass index $(\mathrm{p}<0.05)$. The mean 6-MWD and $\mathrm{VO}_{2}$ max were $350.6 \pm 54.7 \mathrm{~m}$ and 9.74 $\pm 1.5 \mathrm{ml} / \mathrm{kg} / \mathrm{min}$ respectively. There were significant correlations between functional capacity and each of ESE $(r=0.184 ; p=0.026)$ and SoS $(r=0.374 ; p=0.021)$. Conclusions: Psychosocial correlates

*Corresponding author.

How to cite this paper: Awotidebe, T.O., Adeyeye, V.O., Ativie, R.N., Adedoyin, R.A., Borode, A.O., Balogun, M.O. and Akindele, M.A. (2016) Functional Capacity and Psychosocial Correlates of Exercise in Nigerian Patients with Hypertension. International Journal of Clinical Medicine, 7, 464-473. http://dx.doi.org/10.4236/ijcm.2016.77051 
of exercise including self-efficacy and social support were significantly associated with functional capacity among Nigerian patients with mild to moderate hypertension.

\title{
Keywords
}

\author{
Functional Capacity, Psychosocial Correlate, Exercise, Hypertension
}

\section{Introduction}

Regular exercise practice such as brisk walking, cycling or jogging of moderate intensity and 30 minutes per day has been reported to be effective for blood pressure (BP) control [1]. Exercise alone has been reported to be capable of lowering systolic blood pressure up to $15 \mathrm{mmHg}$ and reduces risk of cardiovascular mortality by $30 \%$ [2]. Although hypertension impairs endothelial function and poor functional capacity, regular exercise participation has been reported to improve aerobic performance and exercise tolerance [3]. Physiotherapists often prescribe exercise training based on cardiovascular parameters and functional status of patients with hypertension. However, individual factors as regard initiation and maintenance of exercise programme are still a challenge in rehabilitation care [4].

Engagement in regular physical exercise may be influenced by many factors including personal and health challenges, lack of recreational facilities, environmental factors and socioeconomic status (SES) [5]. Socioeconomic disparity is a strong determinant of health, and has been reported as an aetiological factor in the development of hypertension [6]. Low SES could negatively impact on self-esteem and ability to engage in self-regulatory task such as exercise [7]. In addition, the social cognitive theory explains that self-efficacy, perceived exercise barrier and social support are central to behaviour change [8].

Exercise as a health behaviour is associated with one's self-efficacy perception and one's ability to overcome self-reported perceived barrier to exercise [9]. King [10] observed that psychosocial factors are important personal attributes that may predict current and future participation in regular physical exercise. However, there is no evidence to suggest that psychosocial factors are taken into consideration in designing exercise training during rehabilitation of patients with hypertension. Furthermore, there is dearth of information on the relationship between functional capacity and psychosocial correlates of exercise among patients with hypertension in different socioeconomic strata. Hence, this study investigated the relationship between functional capacity and psychosocial correlates of exercise among Nigerian patients with hypertension.

\section{Methods}

\subsection{Study Sample}

Participants for this study were patients with clinical diagnosis of essential hypertension. Eligibility for participation included patients with mild to moderate hypertension $(\geq 140 / 90 \leq 179 / 109 \mathrm{mmHg})$ receiving treatment at OAUTHC and whose ages range from 40 - 70 years. They were excluded from the study if presented with musculoskeletal or neurological conditions that may affect walking or cognitive problem affecting ability to recall personal information.

This quasi-experimental study recruited 120 patients with mild to moderate hypertension from the Cardiac Care Unit, Obafemi Awolowo University Teaching Hospitals Complex (OAUTHC), Ile-Ife, Nigeria using purposive sampling technique. The OAUTHC was founded on integrated comprehensive health-care services based on a pyramidal structure designed to secure excellent and efficient health-care services in the area of cardiovascular disease. The hospital has more than 600 beds space. The institution provides health-care to more than 10 million Nigerians in the South West Zone of Nigeria. It covered Ondo, Osun, Oyo, Ekiti, Edo and part of Kwara State [11].

\subsection{Procedure}

Ethical approval for this study was obtained from the Health and Research Ethics Committee of the Institute of 
Public Health, Obafemi Awolowo University, Ile-Ife. The Head of CCU gave permission to recruit patients with hypertension for participation in the study. The purpose of the study was explained to respective participants and an informed consent was obtained. Anti-hypertensive medications and dosage prescribed by the attending cardiologist were recorded. Participants' anthropometric characteristics were measured using standard procedures. After ten minutes of quite sitting, participants' cardiovascular parameters including resting heart rate, systolic and diastolic blood pressure were measured in sitting position using standard procedures.

Functional capacity was assessed using the six minute walk test on a $30 \mathrm{~m}$ level ground floor. After five minute of resting, participants were instructed to perform self-paced walking exercise for 30 minutes. Thereafter, psychosocial factors related to exercise including exercise self-efficacy, social support, perceived exercise barrier and socioeconomic status were assessed.

\subsubsection{Assessment of Functional Capacity}

The six-minute walk test (6-MWT) was performed on a 30 meter level corridor without any obstructing object using the American Thoracic Society guidelines [12]. Participants were allowed to rest for a period of 10 minutes in sitting position before the commencement of the exercise test. Participants were instructed to walk from the starting point to the end at their own selected pace while attempting to cover as much ground as possible in six minutes [13]. Encouragement was provided every 30 seconds or more in a standardized manner by saying: "You are doing well" or "Keep up the good work". The total distance covered during the six minute walk was recorded. The maximum oxygen consumption $\left(\mathrm{VO}_{2}\right.$ max) was estimated using the American College of Sport Medicine predictive equation [14].

Computation: $\mathrm{VO}_{2} \max \left(\mathrm{ml} / \mathrm{O}_{2} \mathrm{~kg} / \mathrm{min}\right)=$ speed $(\mathrm{m} / \mathrm{min}) \times 0.1 \mathrm{~m} / \mathrm{O}_{2} / \mathrm{Kg}+3.5 \mathrm{~m} / \mathrm{O}_{2} / \mathrm{Kg} / \mathrm{min}$

\subsubsection{Self-Paced Walking Exercise}

Self-paced walking exercise was prescribed and carried out by the participants to test their understanding of ability to initiate and maintain such exercise programme on regular basis. Participants were instructed to walk on a $30 \mathrm{~m}$ level ground corridor for 30 minutes. They were allowed to rest briefly for 2 minutes at intervals if experiencing fatigue. At the end of 30 minutes of self-paced walking, cardiovascular parameters were assessed after 10 minutes in sitting position. Thereafter, psychosocial correlates of exercise were assessed using validated questionnaires.

\subsubsection{Assessment of Psychosocial Correlates of Exercise}

\section{Exercise self-efficacy}

Exercise self-efficacy (ESE) was assessed using the exercise self-efficacy scale. The scale was adapted from the study by Kroll et al. [15]. The questionnaire contains questions about level of confidence the participant can demonstrate to engage in exercise under specific circumstances. The questionnaire contains 10 items that describe the participant's confidence to exercise such as "when I am tired", "even if I had no access to a gym or training facility" etc. The questions were rated on a 4-point Likert scale that ranges from "Not at all true (1)" to "exactly true (4)". The maximum obtainable score is 40 while the minimum score is 10.

\section{Social support}

The amount of social support (SoS) available to the respondents was measured using the MOSSSQ. The scale is a 19-item scale developed by Sherborne and Stewart [16]. The instrument consists of four separate social support subscales and an overall functional social support index. A higher score for an individual scale or for the overall support index indicates more support. Each item is scored on a 5-point Likert scale and the scores indicate the degree to which the respondent agrees or disagrees with a particular item question ( $1=$ none of the time, 5 = all of the time). The minimum possible score is 19 which indicates low social support and the maximum possible score is 95.

\section{Perceived exercise barrier}

The barrier component of the exercise benefits/barriers scale (EBBS) developed by Sechrist et al. [17] was used to assess the perceived exercise barrier (PEB) of participants. The barrier component of the EBBS which could be used separately as described by the authors consists of 14 items which is rated on a 4-point Likert-type scale. The barrier component comprised 14 barrier items categorized into four subscales: exercise milieu; time expenditure; physical exertion; and family discouragement. The minimum score for the barrier scale is 14 indicating less perceived barriers to physical activity while the maximum score is 56. Obtained scores for each of 
ESE, SoS and PEB were divided by total possible score and multiplied by 100 to obtain percentage scores; 100 $\times$ (observed score - minimum possible score)/(maximum possible score - minimum possible score). Furthermore, the $25^{\text {th }}, 50^{\text {th }}$ and $75^{\text {th }}$ percentiles was used to label transformed-scores into lower, middle and upper quartiles representing "low", "moderate” and "high” levels for each of psychosocial factor.

\subsubsection{Socio-Economic Status}

Socio-economic Status (SES) was assessed using the SES questionnaire. The questionnaire took 4 major SES indicators into consideration which include educational level, occupation, present salary, and other valuable items. Valuable properties in Nigerian context such as landed properties, type of apartment, number of rooms and persons in the household, cooking utensils, home appliances and electronics such as radio, television and computer were included. Information on vacation in the last one year was also sought. Participant's position in the society including community leader, high chief or religion leader such as priest or imam was also sought. Scores were assigned to each item on the questionnaire based on their status in the Nigerian society. The summative scores of the three socioeconomic indicators and respective valued properties and position in the community were added together to yield a maximum obtainable score of 27 points. The score was transformed as $100 \times$ (observed score - minimum possible score)/(maximum possible score - minimum possible score). The $25^{\text {th }}, 50^{\text {th }}$ and $75^{\text {th }}$ percentiles was used to label transformed-scores into lower, middle and upper quartiles representing "low", "moderate" and "high" levels of socioeconomic class. The instrument has good test re-test reliability value $(\mathrm{r}=0.86)[18]$.

\subsection{Statistical Analyses}

Descriptive statistics of frequency, percentages, mean and standard deviation were used to summarize data. Independent t-test was used to compare male and female exercise self-efficacy, social support, perceived exercise barrier. Furthermore, paired t-test was used to compare pre- and post-exercise cardiovascular parameters (systolic and diastolic blood pressure and heart rate). Pearson product moment correlation was used to test the relationship between psychosocial correlates of exercise and functional capacity. Alpha level was set at $\mathrm{p}<0.05$. SPSS version 16 was used for statistical analysis.

\section{Results}

The socio-demographic characteristics of participants were presented in Table 1. Figure 1 shows distributions of psychosocial factors of all participants. A majority of the participants demonstrated high self-efficacy (75.0\%), moderate social support (60.9\%) and low perceived exercise barrier (71.7\%). More than half, (58.4\%) of the participants were in the middle SES. Table 2 shows the independent t-test comparison of physical characteristics, exercise self-efficacy (ESE), social support (SoS), perceived exercise barrier (PEB), socioeconomic status (SES) and six minute walk distance (6 MWD) between male and female. Both genders were comparable in physical characteristics except in body mass index $(\mathrm{p}<0.05)$. The mean psychosocial correlates of exercise between males and females were also comparable. The mean 6-minute walk distance (6 MWD) and estimated maximum oxygen consumption $\left(\mathrm{VO}_{2} \max \right)$ of all participants were $350.6 \pm 54.7 \mathrm{~m}$ and $9.74 \pm 1.5 \mathrm{ml} / \mathrm{kg} / \mathrm{min}$ respectively.

Table 3 shows the results of cardiovascular response to self-paced walking exercise. The results showed that there were significant differences between pre- and post-exercise, SBP $(p=0.019)$ and heart rate $(p=0.042)$ respectively. Table 4 shows the Pearson Product Moment Correlation between functional capacity and psychosocial correlates of exercise. There were significant correlations between functional capacity and each of ESE $(\mathrm{r}=$ 0.184, $p=0.046)$ and SoS $(r=0.374 ; p=0.031)$ and but not with PEB $(r=0.108 ; p=0.269)$ and SES $(r=-0.03$; $\mathrm{p}=0.669)$.

\section{Discussion}

The purpose of this study was to investigate the relationship between functional capacity and psychosocial correlates of exercise among patients with mild to moderate hypertension. Participants in this study were found to demonstrate high exercise self-efficacy. This is contrary to the finding of a previous study that patients with chronic non-communicable diseases usually have reduced exercise self-efficacy [19]. The plausible explanation 
Table 1. Socio-demographic characteristics of participants.

\begin{tabular}{|c|c|c|}
\hline Variable & $\mathbf{n}$ & $\%$ \\
\hline \multicolumn{3}{|l|}{ Age group (years) } \\
\hline $40-50$ & 23 & 19.2 \\
\hline $51-60$ & 54 & 45.0 \\
\hline$>60$ & 43 & 35.8 \\
\hline \multicolumn{3}{|l|}{ Sex } \\
\hline Male & 36 & 30.0 \\
\hline Female & 84 & 70.0 \\
\hline \multicolumn{3}{|l|}{ Marital status } \\
\hline Single & 2 & 1.7 \\
\hline Married & 86 & 71.7 \\
\hline Widowed & 32 & 26.6 \\
\hline \multicolumn{3}{|l|}{ Educational level } \\
\hline Primary & 62 & 51.7 \\
\hline Secondary & 46 & 38.3 \\
\hline Tertiary & 12 & 10.0 \\
\hline \multicolumn{3}{|l|}{ Occupation } \\
\hline Artisan/Self-employed & 60 & 50.0 \\
\hline Civil servant & 20 & 16.7 \\
\hline Retiree & 40 & 33.3 \\
\hline \multicolumn{3}{|l|}{ Income (monthly) } \\
\hline$<\# 50 \mathrm{~K}$ & 48 & 40.0 \\
\hline$\# 50$ - \#100K & 65 & 54.2 \\
\hline >\#100K & 7 & 5.8 \\
\hline
\end{tabular}

Key: K: Thousands of Naira.

Table 2. Comparison of physical characteristics, functional capacity and psychosocial correlates of exercise by gender.

\begin{tabular}{ccccc}
\hline & Male $(\mathbf{n}=\mathbf{3 6})$ & Female $(\mathbf{n}=\mathbf{8 4})$ & & \\
\hline Variable & Mean \pm S.D & Mean \pm S.D & t-cal. & p-value \\
\hline Age (years) & $58.3 \pm 9.0$ & $57.5 \pm 7.7$ & 0.448 & 0.655 \\
Weight (Kg) & $72.2 \pm 10.6$ & $71.2 \pm 13.1$ & 0.391 & 0.696 \\
BMI (Kg/m²) & $25.4 \pm 3.7$ & $28.1 \pm 5.6$ & -2.587 & $0.011^{*}$ \\
ESE score (\%) & $74.0 \pm 5.6$ & $72.6 \pm 4.9$ & -0.593 & 0.554 \\
SoS score (\%) & $55.6 \pm 7.1$ & $56.6 \pm 2.7$ & 0.621 & 0.362 \\
PEB score (\%) & $39.3 \pm 4.6$ & $41.8 \pm 5.0$ & 0.127 & 0.601 \\
SES score (\%) & $58.4 \pm 4.3$ & $57.8 \pm 4.9$ & 1.426 & 0.281 \\
6-MWD (m) & $360.6 \pm 48.3$ & $346.3 \pm 56.9$ & 1.310 & 0.193 \\
Est. VO VO $_{2}$ max (ml/kg/min) & $10.1 \pm 1.4$ & $9.71 \pm 1.6$ & 1.310 & 0.193 \\
\hline
\end{tabular}

*Significance at p < 0.05. Key: BMI: Body mass index, ESE: Exercise self-efficacy, SoS: Social support, PBE: Perceived exercise barrier, SES: Socio-economic Status, 6 MWD: 6-minute walk distance Est. $\mathrm{VO}_{2}$ max: Estimated maximum oxygen consumption. 


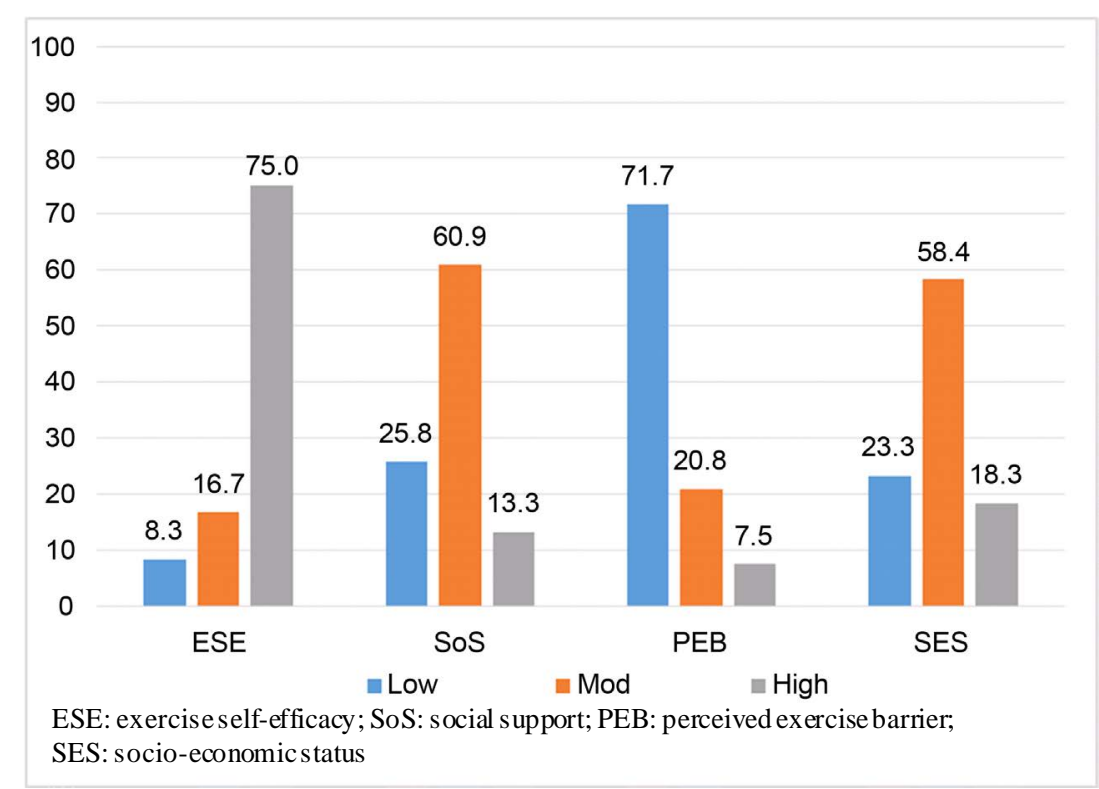

Figure 1. Distributions of psychosocial factors of all participants.

Table 3. Cardiovascular response to self-paced walking exercise.

\begin{tabular}{ccccc}
\hline Variable & Pre & Post & t-cal & p-value \\
\hline Systolic BP (mmHg) & $135.2 \pm 16.3$ & $128.9 \pm 15.3$ & 1.292 & $0.019^{*}$ \\
Diastolic BP (mmHg) & $82.3 \pm 10.2$ & $80.0 \pm 10.5$ & 0.262 & 0.794 \\
Heart rate (beat/minute) & $78.5 \pm 11.6$ & $72.6 \pm 11.3$ & 1.118 & $0.042^{*}$ \\
RPP $\left(\mathrm{X} 10^{3}\right)$ & $10.6 \pm 2.2$ & $10.3 \pm 1.9$ & 0.696 & 0.487 \\
\hline
\end{tabular}

*Significant at $\mathrm{p}<0.05$. Key: BP—Blood Pressure, RPP—Rate Pressure Product.

Table 4. Relationship between functional capacity and psychosocial correlates of exercise.

\begin{tabular}{ccc} 
& Functional Capacity & \\
\hline Variable & $\mathbf{r}$ & $\mathbf{p}$ \\
\hline ESE (\%) & 0.183 & $0.026^{*}$ \\
SOS (\%) & 0.374 & $0.031^{*}$ \\
PEB (\%) & 0.108 & 0.269 \\
SES (\%) & -0.039 & 0.669 \\
\hline
\end{tabular}

*Significant at $\mathrm{p}<0.05$. Key: ESE-Exercise self-efficacy, SoS—Social support, PEB—Perceived exercise barrier, SESSocio-economic status.

for the difference between our study and that of Adeniyi's findings may be that our study participants presented with less severe hypertension and were on regular antihypertensive medications with good blood pressure control. There is evidence from previous studies that self-efficacy is a strong determinant and mediating factor for high level of physical activity as well as better predictor of exercise practice [20] [21]. Kim [21] further emphasized that individuals with high self-efficacy were more likely to engage in exercise behaviour than those with low exercise self-efficacy. In addition, Bandura [22] posited that the key determinant of exercise participation is self-efficacy. Findings from our study do not suggest that there was gender difference in exercise self-efficacy. This is contrary to the findings of previous studies that men usually demonstrate higher self-efficacy than women [23] [24].

Functional capacity is a measure of cardiorespiratory fitness and determinant of survival in cardiovascular 
disease. Hypertension is associated with reduction in functional capacity and impairment of aerobic exercise performance [25]. Our study shows that participants demonstrated moderate functional capacity. The mean 6-minute walk distance (6 MWD) in this study was $350.6 \pm 54.7 \mathrm{~m}$ and estimated maximum oxygen consumption was $9.74 \pm 1.5 \mathrm{ml} / \mathrm{kg} / \mathrm{min}$. This finding is similar to that of Cahalin's et al. [26] who reported a mean value of $357 \mathrm{~m}$ among patients with heart failure. However, Stevens et al., [27] reported higher mean 6 MWD and estimated maximum oxygen consumption of $630 \mathrm{~m}$ and $17.5 \mathrm{ml} / \mathrm{kg} / \mathrm{min}$ respectively among healthy adults. Several factors such as age, presence of chronic disease, initial cardiorespiratory fitness, participants' mood, body weight and individual differences may account for low functional capacity [12] [28]. Furthermore, Fagard et al. [29] reported that some anti-hypertensive medications including both single-dose and short-term diuretics treatments adversely affect exercise capacity and the duration of prolonged sub-maximal exercise.

Low functional capacity is associated with morbidity and mortality in cardiovascular disease [30]. The present study shows that there are positive correlations between functional capacity, exercise self-efficacy and social support. In agreement with findings of previous studies, strong relationship has been reported to be existing between functional capacity, self-efficacy and exercise behaviour in patients with coronary heart disease [31] [32]. In addition, Cromwell and Adams, [33] submitted that there is a strong association between level of exercise participation and exercise self-efficacy among older African-Americans with or without cardiac challenges.

High level of confidence to engage in regular exercise might not be enough to increase exercise participation and adherence but it is possible to initiate and sustain exercise practice among individuals with high exercise self-efficacy due to inherent self-regulatory mechanism to overcome specific task with resultant improvement in functional capacity [34]. A study by Cohen-Mansfield et al. [35] identified some key determinants of exercise participation and grouped them into two main categories as either increase adherence to exercise (motivators) or decrease adherence to exercise (barriers). However, our study did not find significant correlation between perceived exercise barrier and functional capacity. The type of exercise adopted in our study; self-paced walking of single exercise treatment might be responsible for no correlation.

There is significant correlation between functional capacity and social support. This finding corroborates a previous study that social support enhances regular exercise participation and improved functional capacity in patients with cardiac challenges [36]. Similarly, Ostergren et al. [37] reported that social support predicted improvement in physical working capacity among a small group of persons admitted with first-time myocardial infarction. Although mechanism through which social support improves functional capacity is still unclear, physical and emotional support from family, spouse or friends might be an important factor that synergies motivation for more efforts during exercise performance. This implies that social support is likely to play key role as a psychological factor that may assist in the prevention of health problems and enhance ability to initiate and sustain behaviour change. Furthermore, the evidence linking social support to health outcomes depends on the severity and nature of health problems investigated. Although mild to moderate hypertension is usually asymptomatic and might be less distressing, social support has been shown to lower cardiovascular reactivity in some laboratory studies [38] [39].

Finding from our study did not show significant correlation between functional capacity and socioeconomic status. This is contrary to finding of a previous study that socioeconomic status (SES) is significantly associated with exercise participation [40]. Socioeconomic status is also believed to be a mediator of psychosocial determinants of physical exercise which may lead to poor self-esteem [41]. In addition, Gallo et al. [42] reported that socioeconomic disparity is an important mediator of exercise participation. In this part of the world, SES is relatively a burgeoning area of social determinant of health and rehabilitation, and its assessment is still a challenge in determining the relationship between exercise practice and health outcomes.

Exercise plays significant role in blood pressure control. Our study affirm finding of a previous study that exercise is capable of lowering heart rate and systolic blood pressure in a single treatment [43]. This phenomenon was described as "post exercise hypotension" and many explanations including vascular responsiveness, neurohumoral and structural adaptations have been proposed as the mechanisms behind blood pressure reduction in a single exercise treatment [43] [44]. It is also possible that the role of psychosocial factors might not be unconnected with blood pressure reduction as cardiovascular reactivity decrease has been reported in some previous studies [39] [45]. Notable limitations in our study include the design; this is a quasi-experimental study and causal inferences cannot be made because of the inability to determine temporal sequence. Participants in our study were placed on different anti-hypertensive medications and it is possible that some of the medications might mask functional capacity during exercise practice. In addition, exercise self-paced walking in a single exercise 
treatment might not be adequate enough to prompt exercise self-efficacy, social support and perceived barrier to exercise. Furthermore, participants in this study were recruited from hospital and were using antihypertensive medications on regular basis who might not be true representative of patients with hypertension in Nigeria.

\section{Conclusion}

In conclusion, exercise self-efficacy and social support were significantly associated with functional capacity but not with perceived exercise barrier and socioeconomic status in Nigerian patients with mild to moderate hypertension. Exercise prescription and training usually employ cardiovascular parameters and functional capacity as the basis to guide exercise commencement and progression, however, psychosocial factors related to exercise are becoming relevant for effective initiation and maintenance of exercise practice. Hence, psychosocial correlates of exercise should be regularly investigated and incorporated into the mainstream care of patients with cardiovascular disease prior to and during exercise rehabilitation programme in order to enhance adherence and beneficial cardiovascular health outcomes. Population based intervention studies are needed to further evaluate the role of psychosocial correlates of exercise in hypertension.

\section{Acknowledgements}

The authors wish to thank the Consortium for Advanced Research Training in Africa (CARTA) for providing technical support. CARTA is jointly led by the African Population and Health Research Center and the University of the Witwatersrand and funded by the Wellcome Trust (UK) (Grant No: 087547/Z/08/Z), the Department for International Development (DfID) under the Development Partnerships in Higher Education (DelPHE), the Carnegie Corporation of New York (Grant No: B 8606), the Ford Foundation (Grant No: 1100-0399), Swedish International Development Corporation Agency—SIDA (grant: 54100029), Google. Org (Grant No: 191994), and MacArthur Foundation Grant No: 10-95915-000-INP.

\section{Presentation}

Abstract of this study was presented at the $9^{\text {th }}$ World Confederation for Physical Therapy (WCPT) Congress in Singapore, 1-4 May, 2015.

\section{Conflict of Interest}

The authors declared none.

\section{References}

[1] American College of Sport Medicine (2006) ACSM’s Guidelines for Exercise Testing and Prescription. 7th Edition, Lippincott Williams and Wilkins, Philadelphia.

[2] Whelton, S.P., Chin, A., Xin, X. and He, J. (2002) Effect of Aerobic Exercise on Blood Pressure: A Meta-Analysis of Randomized, Controlled Trials. Annals of Internal Medicine, 136, 493-503. http://dx.doi.org/10.7326/0003-4819-136-7-200204020-00006

[3] Madssen, E., Arbo, I., Granøien, I., Walderhaug, L. and Moholdt, T. (2014) Peak Oxygen Uptake after Cardiac Rehabilitation: A Randomized Controlled Trial of a 12-Month Maintenance Program versus Usual Care. PLoS ONE, 9, e107924. http://dx.doi.org/10.1371/journal.pone.0107924

[4] Walcott-McQuigg, J.A. and Prohaska, T.R. (2001) Factors Influencing Participation of African American Elders in Exercise Behavior. Public Health Nursing, 18, 194-203. http://dx.doi.org/10.1046/j.1525-1446.2001.00194.x

[5] Pan, S.Y., Cameron, C., Des Meules, M., Morrison, H., Craig, C.L. and Jiang, X. (2009) Individual, Social, Environmental, and Physical Environmental Correlates with Physical Activity among Canadians: A Cross-Sectional Study. BMC Public Health, 9, 21-29. http://dx.doi.org/10.1186/1471-2458-9-21

[6] Chen, G.E. and Miller, E. (2013) Socioeconomic Status and Health: Mediating and Moderating Factors. Annals of Review Clinical Psychology, 9, 723-749. http://dx.doi.org/10.1146/annurev-clinpsy-050212-185634

[7] de Ridder, D., Geenen, R., Kuijer, R. and van Middendorp, H. (2008) Psychological Adjustment to Chronic Disease. The Lancet, 372, 246-255. http://dx.doi.org/10.1016/S0140-6736(08)61078-8

[8] Bandura, A. (1997) Self-Efficacy: The Exercise of Control. W.H. Freeman, New York.

[9] Dishman, R.K., Saunders, R.P., Motl, R.W., Dowda, M. and Pate, R.R. (2009) Self-Efficacy Moderates the Relation between Declines in Physical Activity and Perceived Social Support in High School Girls. Journal of Pediatric 
Psychology, 34, 441-451. http://dx.doi.org/10.1093/jpepsy/jsn100

[10] King, A.C. (2001) Interventions to Promote Physical Activity by Older Adults. Journal of Gerontology: SERIES The Gerontological Society of America, 56, 36-46.

[11] Adedoyin, R.A. and Adesoye, A.T. (2005) Incidence and Pattern of Cardiovascular Diseases in a Nigerian Hospital. Tropical Doctor, 35, 104-106. http://dx.doi.org/10.1258/0049475054037075

[12] American Thoracic Society (2000) ATS Statement: Guidelines for the Six-Minute Walk Test. American Journal of Respiratory and Critical Care Medicine, 166, 111-117.

[13] Adedoyin, R.A., Adeyanju, S.A., Balogun, M.O., Akintomide, A.O., Adebayo, R.A., Akinwusi, P.O. and Awotidebe, T.O. (2010) Assessment of Exercise Capacity in African Patients with Chronic Heart Failure Using the Six-Minute Walk Test. Internal Journal General Medicine, 3, 109-113. http://dx.doi.org/10.2147/ijgm.s5533

[14] American College of Sport Medicine (ACSM) (1995) Prediction of Maximum Oxygen Consumption $\mathrm{VO}_{2}$ Max during Level Walking.

[15] Kroll, T., Kehn, M., Ho, P.S. and Groah, S. (2007) The SCI Exercise Self-Efficacy Scale (ESES): Development and Psychometric Properties. International Journal of Behavioral Nutrition and Physical Activity, 4, 34. http://dx.doi.org/10.1186/1479-5868-4-34

[16] Sherbourne, C.D. and Stewart, A.L. (1991) The Medical Outcomes Survey Social Support Survey. Social Science and Medicine, 32, 705-714. http://dx.doi.org/10.1016/0277-9536(91)90150-B

[17] Sechrist, K.R., Walker, S.N. and Pender, N.J. (1987) Development and Psychometric Evaluation of the Exercise Benefits/Barriers Scale. Research in Nursing and Health, 10, 357-365. http://dx.doi.org/10.1002/nur.4770100603

[18] Adedoyin, R.A., Mbada, C.E., Awofolu, O.O. and Oyebami, O.M. (2005) The Influence of Socioeconomic Status on Casual Blood Pressures of the Adult Nigerians. European Journal of Cardiovascular Prevention and Rehabilitation, 12, 271-273. http://dx.doi.org/10.1097/00149831-200506000-00014

[19] Adeniyi, A.F., Idowu, O.A., Ogwumike, O.O. and Adeniyi, C.Y. (2012) Comparative Influence of Self-Efficacy, Social Support and Perceived Barriers on Low Physical Activity Development in Patients with Type 2 Diabetes, Hypertension or Stroke. Ethiopian Journal Health Sciences, 22, 113-119.

[20] Trost, S.G., Owen, N., Bauman, A.E., Sallis, J.F. and Brown, W. (2002) Correlates of Adults Participation in Physical Activity: Review and Update. Medicine and Science in Sports and Exercise, 34, 1996-2001. http://dx.doi.org/10.1097/00005768-200212000-00020

[21] Kim, Y.H. (2007) Application of the Trans-Theoretical Model to Identify Psychological Construct Influencing Exercise Behavior: A Questionnaire Survey. International Journal of Nursing Studies, 44, 936-944. http://dx.doi.org/10.1016/j.ijnurstu.2006.03.008

[22] Bandura, A. (2004) Health Promotion by Social Cognitive Means. Health Education Behaviour, 31, $143-164$. http://dx.doi.org/10.1177/1090198104263660

[23] Huberty, J.L., Ransdell, L.B., Sigman, C., Flohr, J.A., Schult, B., Grosshans, O. and Durrant, L. (2008) Explaining Long-Term Exercise Adherence in Women Who Complete a Structured Exercise Program. Research Quarterly in Exercise and Sport, 79, 374-384. http://dx.doi.org/10.1080/02701367.2008.10599501

[24] Daley, L.K., Fish, A.F., Frid, D.J. and Mitchell, G.L. (2009) Stage-Specific Education/Counseling Intervention in Women with Elevated Blood Pressure. Prognostic Cardiovascular Nursing, 24, 45-52. http://dx.doi.org/10.1111/j.1751-7117.2009.00031.x

[25] Maruf, F.A., Akinpelu, A.O. and Salako, B.L. (2013) Self-Reported Quality of Life before and after Aerobic Exercise Training in Individuals with Hypertension: A Randomized-Controlled Trial. Journal of Applied Psychology: Health and Well-Being, 5, 209-224. http://dx.doi.org/10.1111/aphw.12005

[26] Cahalin, L.P., Arena, R., Bandera, F., Lavie, C.J. and Guazzi, M. (2013) Heart Rate Recovery after the Six Minute Walk Test (6MWT) Rather than Distance Ambulated Is a Powerful Prognostic Indicator in Heart Failure with Reduced and Preserved Ejection Fraction: A Comparison with Cardiopulmonary Exercise Testing. European Journal Heart Failure, 15, 519-527. http://dx.doi.org/10.1093/eurjhf/hfs216

[27] Stevens, D., Elpern, E., Sharma, K., Szidon, P., Ankin, M. and Kesten, S. (1999) Comparison of Hallway and Treadmill Six-Minute Walk Tests. American Journal of Respiratory Critical Care Medicine, 160, 1540-1543. http://dx.doi.org/10.1164/ajrccm.160.5.9808139

[28] Carter, R., Holiday, D.B., Nwazuruba, C. and Stocks, J. (2003) 6 Minutes’ Walk Work for Assessment of Functional Capacity in Patients with COPD. Chest, 123, 1408-1415. http://dx.doi.org/10.1378/chest.123.5.1408

[29] Fagard, R.H., Staessen, J., Thijs, L. and Amery, A. (1993) Influence of Antihypertensive Drugs on Exercise Capacity. Drugs, 46, 32-36. http://dx.doi.org/10.2165/00003495-199300462-00007

[30] Keteyian, S.J., Brawner, C.A., Savage, P.D., Ehrman, J.K., Schairer, J., et al. (2008) Peak Aerobic Capacity Predicts Prognosis in Patients with Coronary Heart Disease. American Heart Journal, 156, 292-300. 
http://dx.doi.org/10.1016/j.ahj.2008.03.017

[31] Collins, E., Langbein, W.E., Dilan-Keotje, J., et al. (2004) Effects of Exercise Training on Aerobic Capacity and Quality of Life in Individuals with Heart Failure. Heart Lung, 33, 154-161. http://dx.doi.org/10.1016/j.hrtlng.2003.12.009

[32] Bray, S.R. and Brawley, L.R. (2006) Relationship of Proxy Efficacy and Reliance to Home-Based Physical Activity after Cardiac Rehabilitation. Rehabilitation Psychology, 51, 224-231. http://dx.doi.org/10.1037/0090-5550.51.3.224

[33] Cromwell, S.L. and Adams, M.M. (2006) Exercise Self-Efficacy, and Exercise Behavior in Hypertensive Older African-Americans. Journal of National Black Nurses’ Association, 17, 17-21.

[34] McAuley, E., Mullen, S.P., Szabo, A.N., White, S.M., Wójcicki, T.R., Mailey, E.L. and Kramer, A.F. (2011) Self-Regulatory Processes and Exercise Adherence in Older Adults: Executive Function and Self-Efficacy Effects. American Journal of Preventive Medicine, 41, 284-290. http://dx.doi.org/10.1016/j.amepre.2011.04.014

[35] Cohen-Mansfield, J., Marx, M.S. and Guralnik, J.M. (2003) Motivators and Barriers to Exercise in an Older CommunityDwelling Population. Journal of Aging and Physical Activity, 2, 242-253.

[36] Brownson, R.C., Baker, E.A., Housemann, R.A., Brennan, L.K. and Bacak, S.J. (2001) Environmental and policy determinants of physical activity in the United States. American Journal Public Health, 91, 1995-2001. http://dx.doi.org/10.2105/AJPH.91.12.1995

[37] Östergren, P.O., Freitag, M., Hanson, B., Hedin, E., Isacsson, S.O., Odeberg, H. and Svensson, S.E. (1991) Social Netwetwork and Social Support Predict Improvement of Physical Working Capacity in Rehabilitation of Patients with First Myocardial Infarction. Scandinavian Journal of Public Health, 19, 225-234.

[38] Lepore, S.J., Allen, K.A. and Evan, G.W. (1993) Social Support Lowers Cardiovascular Reactivity to an Acute Stressor. Psychosomatic Medicine, 55, 518-524. http://dx.doi.org/10.1097/00006842-199311000-00007

[39] Bernette, P.A., Spence, I.D., Manuck, S.B. and Jennings, J.R. (1997) Physiological Stress and the Progression of Carotid Artery Disease. Journal of Hypertension, 15, 49-55. http://dx.doi.org/10.1097/00004872-199715010-00004

[40] Cerin, E. and Leslie, E. (2008) How Socio-Economic Status Contributes to Participation in Leisure-Time Physical Activity. Social Science and Medicine, 66, 2596-2609. http://dx.doi.org/10.1016/j.socscimed.2008.02.012

[41] Lindström, M., Hanson, B.S. and Ostergren, P.O. (2001) Socioeconomic Differences in Leisure-Time Physical Activity: The Role of Social Participation and Social Capital in Shaping Health Related Behaviour. Social Science and Medicine, 52, 441-451. http://dx.doi.org/10.1016/S0277-9536(00)00153-2

[42] Gallo, L.C., de los Menteros, K.E. and Shivpuri, S. (2009) Socioeconomic Status and Health: What Is the Role of Reserve Capacity? Current Directory of Psychology and Science, 18, 269-274. http://dx.doi.org/10.1111/j.1467-8721.2009.01650.x

[43] Pescatello, L.S., Margauz, G.A., Blanchard, B.E., Kerr, A., Taylor, A.L., Johnson, A.N., Maresh, C.M., Rodriguez, N. and Thompson, P.D. (2004) Exercise Intensity Alters Post Exercise Hypotension. Journal of Hypertension, 22, 18811888. http://dx.doi.org/10.1097/00004872-200410000-00009

[44] MacDonald, J.R., MacDougall, J.D. and Hogben, C.D. (2000) The Effects of Exercising Muscle Mass on Post Exercise Hypotension. Journal of Human Hypertension, 14, 317-320. http://dx.doi.org/10.1038/sj.jhh.1000999

[45] Uchino, B.N., Cacioppo, J.T. and Kiecolt-Glaser, J.K. (1996) The Relationship between Social Support and Physiological Processes. A Review with Emphasis on Underlying Mechanism and Implications for Health. Psychology Bulletin, 119, 488-531. http://dx.doi.org/10.1037/0033-2909.119.3.488

\section{Submit or recommend next manuscript to SCIRP and we will provide best service for you:}

Accepting pre-submission inquiries through Email, Facebook, Linkedin, Twitter, etc A wide selection of journals (inclusive of 9 subjects, more than 200 journals)

Providing a 24-hour high-quality service

User-friendly online submission system

Fair and swift peer-review system

Efficient typesetting and proofreading procedure

Display of the result of downloads and visits, as well as the number of cited articles

Maximum dissemination of your research work

Submit your manuscript at: http://papersubmission.scirp.org/ 